\section{THE FINAL SURVEY INSTRUMENT}

The final survey instrument consists of 285 questions covering 34 content areas. These are shown in Table 3. The survey includes 63 new questions, while the remainder are modified or adopted from previous surveys.

\section{CONCLUSION}

The NSW Child Health Survey will provide essential data on the health status of children in NSW. The process of survey development, overseen by a technical expert group, proved highly successful, resulting in an innovative survey instrument that addresses both established and emerging priority areas in child health. The survey will be conducted in 2001, and we eagerly await the outcome.

\section{REFERENCES}

1. NSW Department Health. The Start of Good Health: Improving the Health of Children in NSW. Sydney: NSW Department of Health, publication number HSP 980130, 1999.

2. Jorm L. Surveillance of child health in NSW: status, gaps and developments. NSW Public Health Bulletin 1998; (9): 73-75.

3. Commonwealth Department of Human Services and Health. The health of young Australians: a national health policy for children and young people. Canberra: AGPS, 1995.

4. Moon L, Rahman N, Bhatia K. Australia's children: their health and wellbeing 1998. Canberra: Australian Institute of Health and Welfare, 1998.

5. Nossar V, Alperstein G. Monitoring child health (editorial). NSW Public Health Bulletin 1998; (9): 71-72. w

\title{
PROGRESS ON FAMILIES FIRST: A SUPPORT NETWORK FOR FAMILIES RAISING CHILDREN
}

\section{Dianne Hudson}

Program Manager, Families First

Office of Children and Young People

Research shows that significant improvements in a child's health, education and welfare can be sustained when early intervention and support services are provided. ${ }^{1,2,3}$ This article describes Families First, a strategy sponsored by the NSW Government to re-shape and develop prevention and early intervention services, which help parents and communities sustain their children's health and wellbeing in the long term.

\section{INTRODUCTION}

Families First is the joint responsibility of Area Health Services, the Departments of Ageing and Disability, Community Services, Education and Training, Health and Housing. Non-government services funded by the NSW Government are also participating.

What follows is a snapshot of how Families First is unfolding in the first group of areas: the Mid North Coast, Far North Coast and South Western Sydney within existing resources and with additional funding of \$3.64 million in 1999-2000. Implementation in these areas started at the end of 1998.

\section{SERVICES UNDER FAMILIES FIRST}

The agencies responsible for Families First are now jointly planning and making decisions together about the direction of Families First within their areas. Changes are being made to how some services support families, other services are being strengthened, and new services are starting around the four fields of activity outlined below.

Supporting parents who are expecting or caring for a new baby

Maternal and child health services have an important role in supporting parents through pregnancy and following the birth of their children. Under Families First, and in line with the Start of Good Health: Improving the Health of Children in NSW (1999), ${ }^{3}$ the focus is to provide accessible healthcare, support and information about parenting. We also want to link parents to other services as soon as possible if there are signs that they are in need of additional support.

\section{Antenatal Care}

Some women, particularly Aboriginal and young women, have difficulty accessing antenatal care and support. To aid these women, we are increasing support during pregnancy by reaching out to them and providing services at home-and in other community settings-where they are more likely to access services.

For example, a new service called the Young Parents Program started in August 1999 in Kempsey. Many pregnant teenagers do not attend the antenatal care clinic at Kempsey Hospital because they don't feel comfortable in this environment. Through Families First, an alternative 
antenatal care clinic has started specifically for this age group. Here they can meet teenagers who are in similar circumstances and, individually or as a group, get advice on how to cope with parenthood.

Also, an antenatal home visiting program for Aboriginal families in Macarthur will soon be piloted through a partnership arrangement between Tharawal Aboriginal Corporation, South Western Sydney Area Health Service, and the Centre for Health Equity Training Research and Evaluation. The outcomes of the program will also be used to determine a more appropriate model for providing maternal and child health services to Aboriginal and Torres Strait Islander families in Macarthur, which can be incorporated into the current system.

\section{Post Natal Care}

Early Childhood and Primary Health Nurses usually support parents and their babies at child health clinics. Families First is increasing home visiting by nurses because research tells us that better outcomes for children can be achieved, and home visiting by nurses is an effective way to reach those families that don't traditionally access clinic-based services.

Mid North Coast, Northern Rivers and South Western Sydney Area Health Services are in the process of increasing the amount of home visiting that they provide. An additional $\$ 1$ million is being spent on employing extra Early Childhood Health Nurses on the North Coast, and more Primary Health Nurses in South Western Sydney, to further expand home visiting services in 2000 .

\section{Supporting parents who are caring for infants and young children}

The focus of Families First is to link families to support each other, and to provide information and advice to help parents understand the needs of their children during the critical first three years. Examples of the types of services being expanded and established are:

\section{Parenting Information}

The Department of Community Services (DOCS) has produced easy-to-read and practical information on raising children for parents. This information is available on the internet at www.community.nsw.gov.au, or by contacting DOCS on (02) 97162255 . Health practitioners may find these resources useful when working with families.

\section{Supported Playgroups}

Supported playgroups are being expanded in several locations and in different settings such as on housing estates and at preschools. The focus is on helping parents without partners, teenage parents or parents who don't have an extended family to help them understand their children's needs and enhance their parenting skills. The playgroups also serve as an access point for services.

\section{Volunteer Home Visiting Services}

Research tells us that this approach can improve family functioning. ${ }^{4}$ Experienced parents will visit parents with children under three years to provide practical support. Families will be referred to these services mainly by antenatal and early childhood health services.

DOCS is completing the selection of non-government organisations to operate services, worth $\$ 955,000$ annually, in 10 communities on the North Coast and in South West Sydney.

\section{Assisting families who need extra support}

For Families First to be successful as a preventative strategy, it is essential that-from the time a woman first seeks antenatal care-links are established between antenatal and early childhood health services and the whole range of government and non-government services that support families.

We are developing a shared understanding of roles and improved referral processes between the range of child and family services, together with setting up some new services and expanding existing services, some of which include:

\section{Family workers}

For families who have more complex needs and who need professional input to help them with their problems. They will work with first time parents, teenage parents and families with special needs. This model is starting in five communities and will be provided by non-government organisations.

\section{Expanded early intervention services}

For families living in northern NSW, with funding from the Ageing and Disability Department. The services earmarked for expansion have been determined through the Families First area planning process.

\section{'Transition-to-school' programs}

Jointly funded by DOCS and the Department of Education and Training, to prepare pre-schoolers for school and to develop pre-reading skills. These programs have been expanded to another five Aboriginal communities.

\section{Strengthening the connections between communities and families}

The research tells us that people's feelings of 'belonging' to the community and trusting community members are linked to a lower risk of child abuse and neglect in that community. ${ }^{5}$ Families First is directing new funds to disadvantaged communities for programs that help link 


\section{FIGURE 1}

\section{WHAT FAMILIES FIRSTIS ALL ABOUT}

Families First is an initiative of the NSW Government to assist families by:

- facilitating a co-ordinated and accessible network of services;

- increasing opportunities for community support.

Families First is promoting a network of prevention and early intervention services which:

- support parents who are expecting or caring for a new baby, by making antenatal and early childhood health services more accessible to parents. A key strategy will involve visiting families at home;

- support parents who are caring for infants and young children, by providing information about parenting and linking isolated parents with trained and supervised volunteers or with a parent-support network;

- assist families who need extra support, by facilitating a team approach to the support of families who need more specialised assistance;

- strengthen the connections between communities and families, by facilitating community projects that help build supportive environments for children and their parents in high need communities.

Families First gives an opportunity for service providers to:

- review the way they work with families using research and evaluation findings

- develop effective linkages with families and other service providers in planning and providing services.

The Families First framework is described in Families First: A Support Network for Families Raising Children which can be downloaded from the Internet at: www.youth.nsw.gov.au/ff, or by phoning the Office of Children and Young People on (02) 92285146.

families to the services they need, and with each other for support.

Much of our focus is on the public housing estates where we are building on the Department of Housing's community renewal strategies and bringing more support to families living in these communities. For example: antenatal care, health care for children, and supported playgroups are some of the services now being delivered to West and South Kempsey estates.

We are expanding the Schools as Communities Centres approach. These centres support disadvantaged families and help them establish a relationship with their local school before their children start school. These centres are usually located in primary schools, and a local coordinator helps families access the support they want and need.

As different communities have different needs, the support provided for families in each centre varies greatly. Families can be supported, for example by:

- encouraging families to immunise their children against infectious diseases;

- having parent support groups where parents can interact, develop friendships and learn more about parenting;

- providing transition-to-school programs so that children are better prepared to start school;

- providing an early childhood health nurse at the centre so that families with a newborn infant can attend after they drop their school age children at school.
Families First is expanding this approach in eight locations, with some operating from local primary schools, and others at settings where other family activities are held.

\section{FAMILIES FIRST EXPANDS}

Families First will be 'rolled out' across NSW over the next four years. Funding of $\$ 54.2$ million will support this expansion. Government agencies have recently commenced the strategy in the second group of areas; Orana Far West, the Hunter and Inner West (Sydney). This covers the Area Health Services of Macquarie, Far West, Hunter and Central Sydney.

\section{REFERENCES}

1. Olds, D. Home Visitation and Maternal Life Course. JAMA, August 27, 1997; (278)8.

2. Berrueta-Clement, JR. Changed Lives: The Effects of the Perry Pre-school Project on Youths Through Age 19. Yipsilanti, MI: High/Scope Educational Research Foundation, 1984.

3. NSW Department of Health. The Start of Good Health: Improving the Health of Children in NSW. Sydney: NSW Department of Health, September 1999.

4. Barker W, Anderson R, and Chalmers C. Child Protection: the Impact of the Child Development Programme. Bristol: University of Bristol, 1991.

5. Garbarino and Sherman. High Risk Neighbourhoods and High Risk Families: The Human Ecology of Child Maltreatment. Child Dev 1980; (51): 188-198. it 